\title{
Hybrid Particle Swarm Optimization Algorithm to solve Profit based Unit Commitment Problem with Emission Limitations in Deregulated Power Market
}

\author{
S. Prabakaran, $\mathrm{PhD}$ \\ Assistant professor, \\ Department of Electrical and \\ Electronics Engineering, \\ SCSVMV University, \\ Kanchipuram, \\ Tamilnadu, India.
}

\author{
V. SenthilKumar, PhD \\ Associate Professor, \\ Department of Electrical and \\ Electronics Engineering, \\ Anna University, \\ Chennai - 600025 , \\ Tamilnadu, India.
}

\author{
S. Kavaskar \\ Associate Professor, \\ Department of Electrical and \\ Electronics Engineering, \\ Panimalar EngineeringCcollege, \\ Chennai - 600123 , \\ Tamilnadu, India.
}

\begin{abstract}
This paper proposes a new Hybrid Particle Swarm Optimization (HPSO) algorithm that integrates the features of Evolutionary Programming (EP) and Particle Swarm Optimization (PSO) to solve the Profit Based Unit Commitment (PBUC) problem in deregulated power market with emission limitations. The twin objective optimization problem is formulated to maximize the profit of the generation companies and minimize the emission of gaseous pollutants into the atmosphere by satisfying all the system constraints. In this paper, the EP method is applied to solve the 1-0 part of the PBUC problem and PSO method optimizes the economic load dispatch (ELD) which is a sub-problem of PBUC. The concepts of Tabu list (TL) and Aspiration criteria are applied to fine tune the search process in the more promising region of the solution space. The proposed algorithm is verified on IEEE 39 bus system having 10 generating units for 24 hour load pattern. The results obtained are quite encouraging and useful in deregulated power market. The solution of traditional UC and PBUC with and without emission limitations is compared with Improved Artificial Bee's Colony (IABC) algorithm, Shuffled Frog Leaping Algorithm (SFLA), Muller's method and Ant Colony Optimization (ACO) method which are presented in the literature. The comparison of results demonstrates the ability of the proposed algorithm for obtaining maximum profit with minimum emission level.
\end{abstract}

\section{Keywords}

Evolutionary Programming, Particle Swarm Optimization, Emission Limitations, Economic Load Dispatch, Profit Based Unit Commitment, Tabu List.

\section{INTRODUCTION}

Power system restructuring and deregulation have revolutionized the area of modern power system operation and control all over the world. In the construction, operation and maintenance of restructured electric power systems, electrical engineers have to take many technological and managerial decisions at several phases. The final objective of all such decisions is either to maximize the desired gain or to minimize the sweat or time required which ultimately optimizes the solution of the problem undertaken by taking into account the various constraints. The profit based unit commitment is a combinatorial optimization problem in restructured power market which really needs an efficient optimization technique.
The conventional unit commitment is a nonlinear mixed integer optimization problem to find the on/off status and power output levels of all the available generating units in a power pool such that the total production cost is minimum while satisfying all the system constraints [1]. The exhaustive enumerative technique is capable of obtaining global solution to Unit Commitment (UC) problem but consumes more execution time for problems of larger size. Many conventional methods such as Priority List method (PL), Dynamic Programming method (DP), Lagrangian Relaxation method (LR) and Evolutionary Computing methods are available to solve UC problems $[1,2]$. The speed of convergence in PL method is high but gives solution with higher operating cost for large scale problems. The DP approach is capable of solving large scale problems but its complexity increases with increase in number of constraints. Since the dimension of the solution space increases with increase in number of constraints, the possible number of solutions in the solution space also increases. LR method is the approximate method for solving the large scale unit commitment problems in which the Lagrangian multipliers are introduced to penalize the violation of inequality constraints [3].

The Unit Commitment Problem (UCP) in the vertically integrated market is to find the on / off status and the power output level of all the available generating units in the power pool for the load cycles with an objective of minimizing total production cost [5]. The optimal unit commitment solution is the one for which the total production cost is minimum over the time interval while satisfying the power balance equation and all the system constraints [6]. In the past three decades, power industries in the vertically integrated electricity market have undergone the process of deregulation. Restructuring and deregulation of the electric power industries is a very complex exercise first introduced by Chile in 1978. Deregulation of power sector opens the door for private investors to invest their money in the field and hence the financial burden of the federal governments reduced [4]. Many countries like England, Bolivia, Columbia, Norway, Brazil, China and India have successfully disintegrated their electric utility services into the basic parts of generation, transmission and distribution. The open market environment has been created by the market based competition of deregulated power market. It provides customers the freedom of purchasing cheaper power from any supplier and enables the supplier to go for different generation options to serve the consumers at a cheaper price. 
The Profit Based Unit Commitment problem (PBUC) is the suitable form of unit commitment for a generation company (GENCO) in a restructured electricity market. The term 'obligation to serve' has been removed and the generation company's primary objective is maximization of their profit for the quick return of the invested money. So the GENCO's may prepare a schedule with power production less than the demand if it is more profitable to the company [7]. The difference power will be met out by Independent System Operator (ISO) through other options. According to the United Nations Framework Convention on Climate Change, the Kyoto Protocol is an international agreement for reducing the emission level from 37 industrialized countries. In Kyoto protocol, the reference year is 1990 and has the objective of reducing the emission of green house gases by at least $5 \%$ below the value of base year in the commitment period 200812. The main pollutants emitted into the atmosphere are oxides of carbon, oxides of sulphur and oxides of nitrogen. The Kyoto protocol guidelines the countries to reduce their emission level form sectors like oil refineries, steel industries, paper mills, cement industries and ceramic and glass manufacturing companies. The emission trading is allowed in the Kyoto protocol which implies new restrictions on coal based thermal power generating units [12].

Ritcher and Sheble proposed a Genetic Algorithm (GA) based solution for the PBUC problem but GA fails to do local search in the high performance region of the solution space [8]. The Lagrangian Relaxation method has been integrated with Evolutionary Programming for solving the PBUC problem but the method has the same limitations of GA in exploring the high performance region of the solution space [9].Yuan Xiaohui et al have applied improved particle swarm optimization for the PBUC solution but the PSO has the demerits of premature convergence and more computation time [10]. The Muller's method has been applied by Chandran et al for the solution of profit based unit commitment problem. Columbus Christopher et al have proposed ant colony optimization for the PBUC problem but balancing the exploitation and exploration of the solution space by the ants is a big challenge [11]. A hybrid artificial immune system approach has been proposed by Lakshmi et al for the profit based unit commitment solution but emission limitations have not been added in the problem formulation [25]. Swarm intelligence based Improved artificial bee's colony optimization algorithm (IABC) has been formulated by Shanmuga sundaram et al for the solution of PBUC and traditional UC [26].

Gent and Lamont are the pioneers in the emission dispatch of thermal generating units with an objective of minimizing the emission level [13]. Nanda et al have proposed a conventional method for the economic and emission dispatch by considering the line flow limits as an additional constraint [14]. Hota et al have proposed the sequential quadratic programming method for the solution of economic and emission dispatch with line flow limits [15]. Shuffled Frog Leaping Algorithm (SFLA) which is based on the foraging behaviour of frogs has been proposed by Venkatesan et al for the solution of PBUC problem with emission limitations [16]. But the SFLA method has the demerit of premature convergence due to the fact that the frog's jump in the local exploration may slow down the convergence speed.

In this paper, the important planning problem of restructured power system, the profit based unit commitment problem is solved by the proposed hybrid PSO algorithm with an objective of maximizing the GENCO's profit after considering the emission limitations imposed by the Kyoto protocol. The concepts of Tabu list and Aspiration criterion are introduced to fine tune the more promising region of the search space to get better solution which may be near global optimal solution [5]. The IEEE 39 bus test system with 10 generating units has been solved by proposed algorithm for traditional unit commitment, profit based unit commitment and PBUC with emission limitations. The results obtained by the proposed algorithm for traditional UC has been compared with SFLA method and IABC algorithm. The solution obtained for profit based unit commitment without emission limitations has been compared with Muller's method, ACO method and IABC algorithm. The PBUC solution with emission limitations by proposed method has been compared with SFLA method.

The paper is organized as follows: Section 2 explains the problem formulation of the profit based unit commitment with emission limitations, Section 3 presents the algorithmic steps of proposed algorithm and the implementation of EP, PSO and tabu search, Section 4 explains the example problem and simulation results followed by conclusion in the Section 5 .

\section{PROBLEM FORMULATION}

\subsection{Profit Based Unit Commitment}

The main objective of the profit based unit commitment problem is to maximize the total profits of GENCOs subjected to a set of system and unit constraints over the forecasted time horizon. In a power system, the forecasting of load for the future demand is very important due to the fact that the GENCO's commit their units for maximizing their profits based on the assumption that the load is known [28]. The list of variables and their explanation have been included as follows:

\begin{tabular}{|c|c|}
\hline $\mathrm{PF}$ & Total Profit \\
\hline RV & Total Revenue \\
\hline $\mathrm{TC}$ & Total Cost \\
\hline EM & Total Emission \\
\hline $\mathrm{N}$ & Number of generating units \\
\hline $\mathrm{T}$ & Number of time intervals \\
\hline$a_{i}, b_{i}, c_{i}$ & Unit cost coefficients \\
\hline $\mathrm{ST}_{\mathrm{T}}$ & Start up cost \\
\hline $\mathrm{X}_{\mathrm{ti}}^{\mathrm{on}}$ & $\begin{array}{l}\text { Min time that the unit } i \text { has remain } \\
\text { in on state }\end{array}$ \\
\hline $\mathrm{F}\left(\mathrm{P}_{\mathrm{i}}^{\mathrm{t}}\right)$ & Fuel cost of the unit $i$ at interval $t$ \\
\hline $\mathrm{E}\left(\mathrm{P}_{\mathrm{i}}^{\mathrm{t}}\right)$ & Emission from unit $\mathrm{i}$ at interval $\mathrm{t}$ \\
\hline$\alpha_{\mathrm{i},} \beta_{\mathrm{i}}, \gamma_{\mathrm{i}}$ & Emission coefficients \\
\hline $\mathrm{HT}_{\text {cost }(\mathrm{i})}$ & Hot start up cost of unit i \\
\hline $\mathrm{RU}_{\mathrm{i}}$ & Ramp-up rate of unit i \\
\hline $\mathrm{ST}_{\mathrm{i}}$ & Start up cost of unit $i$ \\
\hline gbest & global best \\
\hline $\mathrm{x}_{\mathrm{i}}$ & position of particle $\mathrm{i}$ \\
\hline PDt & Power demand at hour $\mathrm{t}$. \\
\hline Pit & Power output of unit i at hour $t$ \\
\hline Pimin & $\begin{array}{l}\text { Minimum generation capacity of } \\
\text { unit } i\end{array}$ \\
\hline Pimax & $\begin{array}{l}\text { Maximum generation capacity of } \\
\text { unit } i\end{array}$ \\
\hline Uit & On/off status of unit $\mathrm{i}$ at hour $\mathrm{t}$ \\
\hline
\end{tabular}




$\begin{array}{ll}\text { MDTi } & \text { Minimum down time of unit } \mathrm{i} \\ \text { CDcost }(\mathrm{i}) & \text { Cold start up cost of unit } \mathrm{i} \\ \text { RDi } & \text { Ramp-down rate of unit } \mathrm{i} \\ \text { pbest } & \text { particle best } \\ \mathrm{C} 1 \text { and } \mathrm{C} 2 & \text { Acceleration coefficients } \\ \text { vi } & \text { velocity of particle } \mathrm{i} \\ \text { Xtioff } & \text { Min time that the unit } \mathrm{i} \text { has remain } \\ \text { FLAC } & \text { in off state } \\ \text { MUTi } & \text { Full Load Average Cost } \\ \text { SRit } & \text { Minimum up time of unit } \mathrm{i} \\ \text { SPt } & \text { Spinning reserve of unit } \mathrm{i} \text { at hour } \mathrm{t} \\ \text { Rit } & \text { Spot price of unit } \mathrm{i} \text { at hour } \mathrm{t}\end{array}$

The profit based unit commitment problem based on forecasted spot price with profit maximization objective can be represented as,

\section{Maximize $\mathrm{PF}=\mathrm{RV}-\mathrm{TC}$}

The objective function to minimize emission can be represented as

$$
\begin{aligned}
& \text { Minimize } E M=\sum_{\mathrm{t}=1}^{\mathrm{T}} \sum_{\mathrm{i}=1}^{N} \mathrm{E}\left(\mathrm{P}_{\mathrm{i}}^{\mathrm{t}}\right) \\
& \mathrm{E}\left(\mathrm{P}_{\mathrm{i}}^{\mathrm{t}}\right)=\alpha_{\mathrm{i}}\left(\mathrm{P}_{\mathrm{i}}^{\mathrm{t}}\right)^{2}+\beta_{\mathrm{i}}\left(\mathrm{P}_{\mathrm{i}}^{\mathrm{t}}\right)+\gamma_{\mathrm{i}}
\end{aligned}
$$

The revenue and total cost can be calculated from the following equations

$$
\begin{gathered}
\mathrm{RV}=\sum_{\mathrm{t}=1}^{\mathrm{T}} \sum_{\mathrm{i}=1}^{\mathrm{N}}\left[\mathrm{SP}^{\mathrm{t}} \times \mathrm{P}_{\mathrm{i}}^{\mathrm{t}}\right] \times \mathrm{U}_{\mathrm{i}}^{\mathrm{t}} \\
\mathrm{TC}=\sum_{\mathrm{t}=1}^{\mathrm{T}} \sum_{\mathrm{i}=1}^{\mathrm{N}} \mathrm{F}\left(\mathrm{P}_{\mathrm{i}}^{\mathrm{t}}\right)+\mathrm{ST}\left(\mathrm{T}_{\mathrm{i}}^{\text {off }}\right) \times\left[1-\mathrm{U}_{\mathrm{i}}^{\mathrm{t}-1}\right] \mathrm{U}_{\mathrm{i}}^{\mathrm{t}} \\
\mathrm{F}\left(\mathrm{P}_{\mathrm{i}}^{\mathrm{t}}\right)=\mathrm{a}_{\mathrm{i}}\left(\mathrm{P}_{\mathrm{i}}^{\mathrm{t}}\right)^{2}+\mathrm{b}_{\mathrm{i}}\left(\mathrm{P}_{\mathrm{i}}^{\mathrm{t}}\right)+\mathrm{c}_{\mathrm{i}}
\end{gathered}
$$

Where $a_{i}, b_{i}$ and $c_{i}$ are the unit cost coefficients and $\alpha_{i}, \beta_{i}$ and $\gamma_{i}$ are the emission coefficients. The generator start-up cost depends on the time the unit has been switched off prior to the start-up, $\mathrm{T}_{\mathrm{i}}^{\text {off }}$. The overall objective is to maximize profit (PF) and minimize the emission (EM) subjected to a number of system and unit constraints as follows:

\subsection{Power Balance Constraint}

The total generated power at each hour from all the generating units may be less than or equal to the load of the corresponding hour, $\mathrm{PD}^{\mathrm{t}}$

$$
\sum_{\mathrm{i}=1}^{\mathrm{N}} \mathrm{P}_{\mathrm{i}}^{\mathrm{t}} \times \mathrm{U}_{\mathrm{i}}^{\mathrm{t}} \leq \mathrm{PD}^{\mathrm{t}} \text { where } \mathrm{t}=1,2,3, \ldots, \mathrm{T}
$$

\subsection{Power Generation Limits}

When the unit is in ON state, the real power output of the unit 'i' must be within its minimum and maximum generation limits

$$
\mathrm{P}_{\mathrm{i} \text { min }} \leq \mathrm{P}_{\mathrm{i}}^{\mathrm{t}} \leq \mathrm{P}_{\mathrm{i} \text { max }}
$$

With each generating unit, a reserve capacity is allocated which is responsible for maintaining the supply of power during the forced outage of generating unit. This capacity will be in between 0 and the difference between the generation capacity limits of each unit.

$0 \leq \mathrm{R}_{\mathrm{i}}^{\mathrm{t}} \leq \mathrm{P}_{\mathrm{i} \text { max }}-\mathrm{P}_{\mathrm{i} \text { min }}$ Where $\mathrm{i}=1,2,3, \ldots, \mathrm{N}$

\subsection{Minimum up Time}

The committed unit should remain in on state for minimum time before it is turned off and is given by

$$
\mathrm{X}_{\mathrm{ti}}^{\mathrm{on}} \geq \mathrm{MUT}^{\mathrm{t}}
$$

\subsection{Minimum Down Time}

This constraint gives the minimum time for which a switched off unit should remain in off state before it is restarted.

$$
\mathrm{X}_{\mathrm{ti}}^{\mathrm{off}} \geq \mathrm{MDT}^{\mathrm{t}}
$$

\subsection{System power balance and spinning reserve}

The sum of power and reserve of unit $\mathrm{i}$ in the time horizon should be within its minimum and maximum power generation limits. Spinning reserve must be maintained so that the sudden loss of one or more units does not cause too far a drop in system frequency. But in restructured power system, a unit can produce power less than reserve if it is profitable to GENCO'S.

$$
\mathrm{P}_{\mathrm{i} \text { min }} \leq \mathrm{P}_{\mathrm{i}}^{\mathrm{t}} \mathrm{U}_{\mathrm{i}}^{\mathrm{t}}+\mathrm{R}_{\mathrm{i}}^{\mathrm{t}} \mathrm{U}_{\mathrm{i}}^{\mathrm{t}} \leq \mathrm{P}_{\mathrm{i} \max }
$$

If the unit is in ON state, the power output of the unit along with its spinning reserve component should be within its upper and lower bound of power generation limits.

$\sum_{\mathrm{i}=1}^{\mathrm{N}}\left(\mathrm{R}_{\mathrm{i}}^{\mathrm{t}} \mathrm{U}_{\mathrm{i}}^{\mathrm{t}}\right) \leq \mathrm{SR}_{\mathrm{i}}^{\mathrm{t}}$ Where $\mathrm{t}=1,2,3, \ldots ., \mathrm{T}$

The total spinning reserve from all the generating units of GENCO may be less than or equal to the total spinning reserve of the system. If it is less, the difference in spinning reserve will be met by ISO from other options available in the system.

\subsection{Ramp rate limits}

The maximum up ramp and down ramp limits are maximum increase or decrease in power generation of a generating unit from one time period to next time period.

$$
\begin{gathered}
\mathrm{P}_{\mathrm{i} \max }^{\mathrm{t}}=\min \left[\mathrm{P}_{\mathrm{i} \max }, \mathrm{P}_{\mathrm{i}}^{(\mathrm{t}-1)}+\tau \mathrm{RU}_{\mathrm{i}}\right] \\
\mathrm{P}_{\mathrm{i} \text { min }}^{\mathrm{t}}=\max \left[\mathrm{P}_{\mathrm{i} \text { min }}, \mathrm{P}_{\mathrm{i}}^{(\mathrm{t}-1)}-\tau \mathrm{RD}_{\mathrm{i}}\right]
\end{gathered}
$$

Where $\tau=1$ hour is the value for the hourly load cycle. The important values which are necessary for calculating the expected revenue and profit are the expected spot price and reserve price. 


\section{HYBRID PSO ALGORITHM}

The proposed hybrid PSO algorithm integrates the best features of EP and PSO and it is implemented for PBUC problem to maximize the profit with less emission. The search procedure of the proposed algorithm is given below and flow chart is shown in Figure.1.

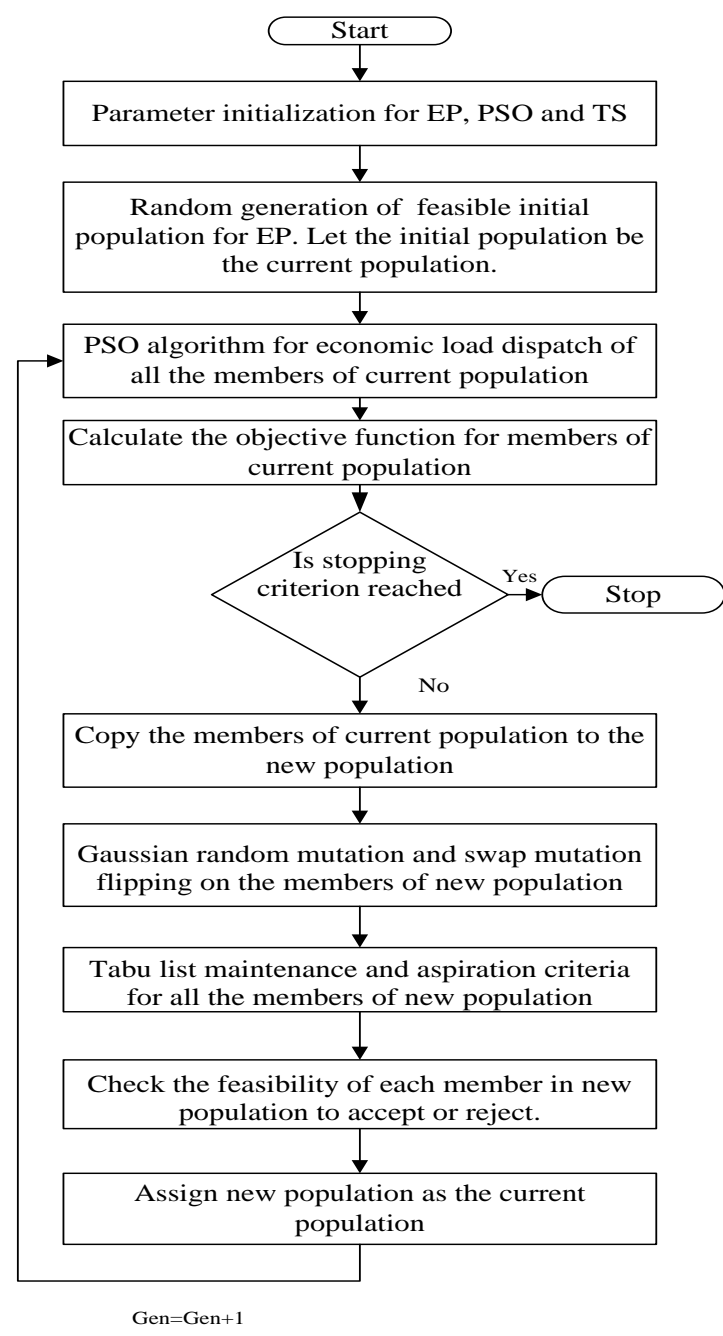

Fig.1 Flowchart for proposed Hybrid PSO Algorithm

1. Start the search process.

2. The parameters such as population size and chromosome length in EP, inertia weight factors, acceleration coefficients and velocity limits of PSO and tabu list size in TS are initialized.

3. The initial population is generated within the range randomly for EP using inbuilt library functions in MATLAB and let the initial population be the current population.

4. The economic load dispatch of all the members of current population is done by particle swarm optimization algorithm.

5. The total profit for all the chromosomes of current population is evaluated from the values of revenue and total cost by $P F=R V-T C$.

6. The maximum number of generations is fixed as stopping criterion and is checked. If it reaches, the program execution goes to step 13, otherwise continued.
7. The members of current population are copied in to the new population

8. The Gaussian random mutation and swap mutation flipping for the members of the current population are done by keeping the repair mechanism to satisfy all the system constraints. The repair mechanism is required due to the fact that the schedule of generators obtained after the mutation operations may violate the system constraints.

9. The tabu list is maintained and the logical aspiration criterion is checked for all the members of the new population to avoid revisiting the already visited solution points.

10. The feasibility of each member in the new population is verified so that the members can be accepted or rejected.

11. The members of new population be made as the members of current population

12. The generation count is increased and the program execution goes to step 4.

13. The search process is stopped and the optimal solution is printed.

\subsection{EP implementation in the proposed algorithm}

The details of the implementation of evolutionary programming components are summarized here as follows:

\subsubsection{Coding of Solution}

A binary matrix of dimension $\mathrm{T} \times \mathrm{N}$ has been used for representing the unit commitment solution. The coding for the proposed algorithm is a mixer of binary and decimal numbers. Each column vector in the solution matrix (Which is the operation schedule of one unit) of length $\mathrm{T}$ is converted to its equivalent decimal number. The solution matrix is then converted in to one row vector (chromosome) of $\mathrm{N}$ decimal numbers $\left(U_{1}, U_{2}, \ldots U_{N}\right)$, each represents the schedule of one unit. The numbers $\mathrm{U}_{1}, \mathrm{U}_{2}, \ldots \mathrm{U}_{\mathrm{N}}$ are integers ranging from 0 to $2^{\mathrm{N}}-1$. Accordingly, a population of size NPOP is stored in a matrix NPOP X N [17]

\subsubsection{Mutation}

The selected chromosome is decoded to its binary equivalent. Then the unit number and time period are randomly selected and the rule of mutation is applied to flip the status of units. If any constraints violated the repair mechanism is applied to revert back to the original position. The Gaussian random mutation is followed in the evolutionary programming part of the proposed algorithm [18].

\subsubsection{Improved Swap Mutation flipping}

After performing mutation, the improved swap mutation flipping is added. The swap operator uses the Average Full Load Costs (AFLC) of the generating units to perform a swap of unit states. The AFLC of a unit is defined as the cost per unit of power when the generator is at its full capacity [19]. When the fuel cost is given by the equation

$$
\mathrm{FC}_{\mathrm{i}}=\mathrm{a}_{\mathrm{i}} \mathrm{P}_{\mathrm{i}}^{2}+\mathrm{b}_{\mathrm{i}} \mathrm{P}_{\mathrm{i}}+\mathrm{c}_{\mathrm{i}}(\mathrm{Rs} / \mathrm{hr})
$$

AFLC can be expressed as

$$
\operatorname{AFLC}_{i}=\frac{c_{i}}{P_{i \max }}+b_{i}+a_{i} P_{i \max }
$$

According to the ascending AFLC values the ranks are given and the corresponding generating units are arranged. The units with lower AFLC should be given higher priority to be dispatched. At a given hour, the operator probabilistically 
swaps the states of two units $i$ and $j$ only, if the unit $i$ is ranked better than unit $\mathrm{j}(\mathrm{i}<\mathrm{j})$ and the state of the units are 'off' and 'on', respectively.

\subsection{PSO Implementation in the proposed algorithm}

A group of particles form a swarm which are moving in a hyperspace for the location of optimal solution in swarm intelligence. The position of each member in a swarm is changed on the basis of its own experience and other members experience in the solution space. Let $\mathrm{x}_{\mathrm{i}}(\mathrm{t})$ be the position of particle $p_{i}$ in solution space at time interval t. The velocity information $\mathrm{v}_{\mathrm{i}}(\mathrm{t})$ has been added with current position to change the position $\mathrm{p}_{\mathrm{i}}$. The influencing factor which forces all the particles towards optimal solution is velocity. The exchange of information between all the particles has been completed by three different phases called individual best, global best and local best[20].

\subsubsection{Individual best and Global best}

The global best (gbest) of PSO is the best particle among the group in the aspects of solution quality. The individual best (pbest) is related to the historical information of a particular particle position [21]. The information of global best and particle best are the social knowledge used to drive the movement of particles towards the optimal solution. In this case the algorithm changes to:

Step 1. Initialize the swarm $p(t)$, of particles such that the position $x_{i}(t)$ of each particle.$p(t)$ is random within the hyperspace, with $t=0$.

Step 2. Evaluate the performance of each particle, using its current position $x_{i}(t)$.

Step 3. Compare the performance of each individual to its best performance so far,

$$
\begin{aligned}
& \mathrm{F}\left[\mathrm{x}_{\mathrm{i}}(\mathrm{t})\right]<\text { pbest }_{\mathrm{i}}, \text { then } \\
& \text { pbest }_{\mathrm{i}}=\mathrm{F}\left[\mathrm{x}_{\mathrm{i}}(\mathrm{t})\right] \\
& \text { xpbest }_{\mathrm{i}}=\mathrm{x}_{\mathrm{i}}(\mathrm{t})
\end{aligned}
$$

Step 4. Compare the performance of each particle to the global best particle,

$$
\begin{aligned}
& \text { If } F\left[x_{i}(t)\right]<\text { gbest then } \\
& \text { gbest }=F\left[x_{i}(t)\right] \\
& \text { xgbest }=x_{i}(t)
\end{aligned}
$$

Step 5. Change the velocity vector for each particle

$$
\mathrm{v}_{\mathrm{i}}(\mathrm{t})=\mathrm{v}_{\mathrm{i}}(\mathrm{t}-1)+\mathrm{c}_{1}\left[\operatorname{xpbest}_{\mathrm{i}}-\mathrm{x}_{\mathrm{i}}(\mathrm{t})\right]+\mathrm{c}_{2}\left[\operatorname{xgbest}_{\mathrm{i}}(\mathrm{t})\right]
$$

Where $c_{1}$ and $c_{2}$ are acceleration coefficients. The second term above is referred as the cognitive component, where as the last term is the social component.

Step 6. Move each particle to a new position:

$$
x_{i}(t)=x_{i}(t-1)+v_{i}(t)
$$

$$
\text { Where } \mathrm{t}=\mathrm{t}+1
$$

Step 7. Go to step 2 and repeat until convergence.

If the objective function information of any particle is away from the global best position and its particle best position, the velocity change required is large to push the particle towards the optimal region.

\subsubsection{Local Best}

The local best and xpbest, reflects the circle neighborhood structure. Particles are influenced by the best position within their neighborhood, as well as their own past experience. Only steps 4 and 5 are changed by replacing xgbest with xpbest. Even though xpbest is slower in convergence than xgbest and xpbest results in much better solution and explores a larger part of the search space [22].

\subsubsection{Fitness Calculation}

The objective of the PSO algorithm is to minimize the total production cost of the power system at each hour by meeting all the system constraints. The cost equation of the generating unit ' $i$ ' at hour $t$ is

$$
\mathrm{F}\left(\mathrm{P}_{\mathrm{i}}^{\mathrm{t}}\right)=\mathrm{a}_{\mathrm{i}}\left(\mathrm{P}_{\mathrm{i}}^{\mathrm{t}}\right)^{2}+\mathrm{b}_{\mathrm{i}}\left(\mathrm{P}_{\mathrm{i}}^{\mathrm{t}}\right)+\mathrm{c}_{\mathrm{i}}
$$

Where $P_{i t}$ is the power output of unit $i$ at hour $t$ and $a_{i}, b_{i}$ and $c_{i}$ are the unit cost coefficients. The startup cost depends on the number of hours the unit is in off state before it is switched on. The procedure of calculating the startup cost is as follows.

$$
\mathrm{ST}_{\mathrm{T}}=\sum_{\mathrm{i}=1}^{\mathrm{N}} \mathrm{H}\left[\mathrm{T}_{\mathrm{i}}(\mathrm{c})\right] \times \mathrm{ST}_{\mathrm{i}}\left[-\mathrm{T}_{\mathrm{i}}(\mathrm{c}-1)\right]
$$

Where

$$
\mathrm{ST}_{\mathrm{i}}\left[-\mathrm{T}_{\mathrm{i}}(\mathrm{c}-1)\right]=\left\{\begin{array}{l}
\mathrm{HT}_{\text {cost(i) }}, \text { if }\left[\mathrm{MDT}_{\mathrm{i}}-\mathrm{T}_{\mathrm{i}}(\mathrm{c}-1)\right] \leq \mathrm{CD}_{\text {hour(i) }} \\
\mathrm{CD}_{\text {cost(i) }}, \text { if }\left[\mathrm{MDT}_{\mathrm{i}}-\mathrm{T}_{\mathrm{i}}(\mathrm{c}-1)\right]>\mathrm{CD}_{\text {hour(i) }}
\end{array}\right\}
$$

The total operating cost over the given time horizon is given by

$$
\mathrm{TC}=\sum_{\mathrm{t}=1}^{\mathrm{T}} \sum_{\mathrm{i}=1}^{\mathrm{N}} \mathrm{F}_{\mathrm{i}}\left(\mathrm{P}_{\mathrm{i}}^{\mathrm{t}}\right) \times \mathrm{U}_{\mathrm{i}}^{\mathrm{t}}+\mathrm{ST}_{\mathrm{T}}
$$

The overall objective of the proposed algorithm is to maximize the profit and minimize the emission.

$$
\text { Fitness function }=\left\{\begin{array}{c}
\text { Max Profit } \\
\text { Min Emission }
\end{array}\right\}
$$

\subsubsection{Convergence}

The PSO algorithm is normally executed for fixed number of iterations and the program will be terminated with best solution obtained so far. Alternatively, a PSO algorithm can be terminated if the velocity changes are close to zero for all the particles, in which case there will be no further changes in particle positions [23].

\subsection{Local Search}

The more promising region of the solution space should be thoroughly searched for locating the best solution for the given problem. This can be incorporated in the proposed 
algorithm by introducing the concepts of tabu list and aspiration criterion.

\subsubsection{Tabu List}

In order to avoid the revisiting of the already visited solution points in the search space the concept of tabu list is followed. These forbidden moves are listed to a certain size and known as tabu. This list is called the tabu list. The quality of the solution is affected by the size of tabu list [24]. The way to identify a good tabu list size is to simply watch for the occurrence of cycling when the size is too small and the deterioration in solution quality when the size is too large, caused by forbidden too many moves [27].

\subsubsection{Aspiration Criterion}

The aspiration criterion is applied to overrule the moves in the tabu list [24]. Different forms of aspiration criteria are used in the literature. The one considered here is a logical aspiration criterion to override the tabu status of a move if this move yields a solution, which has better objective function, than the one obtained earlier with the same move. The main objective of applying aspiration criterion is to add some elasticity in the tabu search by directing it towards the smart progresses.

\section{PROBLEM AND SIMULATION RESULTS}

The proposed algorithm for traditional UC and PBUC problems has been implemented using MATLAB 7.10. For the sake of comparison purpose the developed coding in

MATLAB has been executed on core i3 $(2.1 \mathrm{GHz})$ PC with 4 GB RAM. The algorithm is tested on IEEE 39 bus system having 10 generating units with 24 hour load pattern for getting solutions of traditional UC and PBUC with and without emission limitation. The single line diagram of IEEE39 bus system is shown in Figure 2.

In order to apply the proposed hybrid algorithm, the accurate load forecasting for 24 hours and the spot price for each hour are expected. The general tendency of GENCOs is either to exactly meet the forecasted demand or less than it just to make more profit from the UC schedule prepared. The rest of the issues are taken care of by the Independent System Operator (ISO). The GENCO may prefer the generating units which have less average full load cost. The test system is selected only for the reason of comparing and proving the efficiency of the proposed algorithm. The characteristics and parameters of all the 10 generating units, forecasted load pattern and the expected spot price for 24 hours and emission co-efficients of the IEEE 39 bus test system are shown in Tables 1 - 3 [16]. The coal based thermal power generating units have low operating cost and their cost and emission equations are modeled in quadratic form such as $\left(a_{i} P_{i}^{2}+b_{i} P_{i}\right.$ $\left.+c_{i}\right)$ and $\left(\alpha_{i} P_{i}^{2}+\beta_{i} P_{i}+\gamma_{i}\right)$. The Table 4 gives the parameter selection for the proposed hybrid algorithm. The number of chromosomes means the number of directions in which the proposed algorithm moves in the solution space. Each chromosome in a population is a candidate solution for the PBUC. The 1-0 part of the PBUC is solved by the EP algorithm for which the mutation probability is fixed at 0.05 after trying many values in trial and error basis. The ELD part of the PBUC problem to maximize the profit and minimize the emission is handled by the PSO algorithm for which a size of 20 particles have been selected along with an optimal selection of values for inertia weight factor, velocity limits and acceleration coefficients. The forbidden process of already visited solution points is achieved by maintaining a tabu list with a size of 10 particles. The overruling process of tabu list is achieved by checking a logical aspiration value.

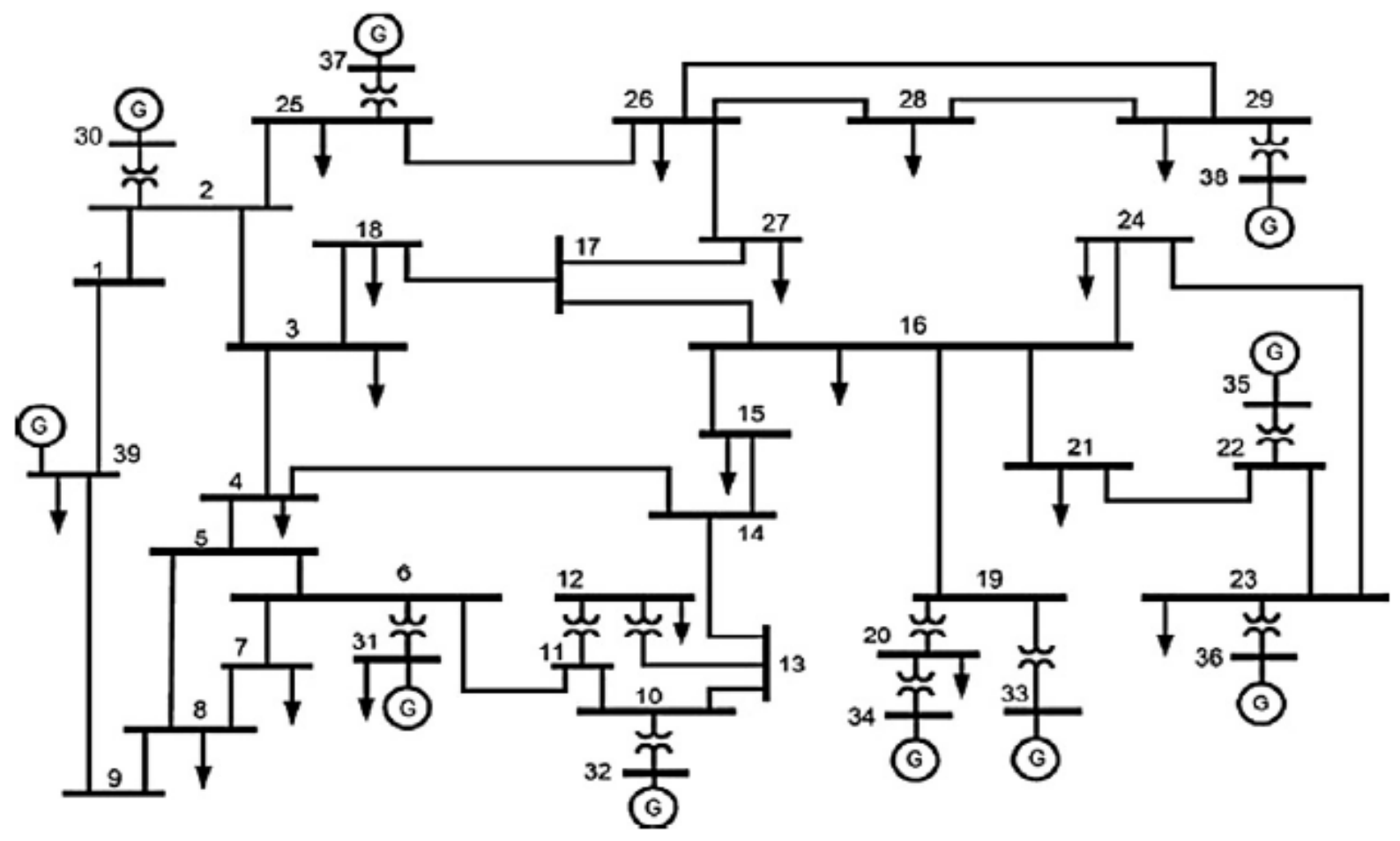

Fig. 2 IEEE 39 Bus System. 
Table 1. Characteristics of 10 generating units

\begin{tabular}{|c|c|c|c|c|c|c|c|c|c|c|}
\hline & Unit 1 & Unit 2 & Unit 3 & Unit 4 & Unit 5 & Unit 6 & Unit 7 & Unit 8 & Unit 9 & Unit 10 \\
\hline $\mathrm{P}_{\mathrm{i}}(\max )$ & 455 & 455 & 130 & 130 & 162 & 80 & 85 & 55 & 55 & 55 \\
\hline $\mathrm{P}_{\mathrm{i}}(\min )$ & 150 & 150 & 20 & 20 & 25 & 20 & 25 & 10 & 10 & 10 \\
\hline $\mathrm{a}_{\mathrm{i}}$ & 0.00048 & 0.0003 & 0.002 & 0.00211 & 0.00398 & 0.00712 & 0.00079 & 0.00413 & 0.00222 & 0.00173 \\
\hline$b_{i}$ & 16.19 & 17.26 & 16.6 & 16.5 & 19.7 & 22.26 & 27.74 & 25.92 & 27.27 & 27.79 \\
\hline $\mathrm{c}_{\mathrm{i}}$ & 1000 & 970 & 700 & 680 & 450 & 370 & 480 & 660 & 665 & 670 \\
\hline $\mathrm{MUT}_{\mathrm{i}}$ & 8 & 8 & 5 & 5 & 6 & 3 & 3 & 1 & 1 & 1 \\
\hline $\mathrm{MDT}_{\mathrm{i}}$ & 8 & 8 & 5 & 5 & 6 & 3 & 3 & 1 & 1 & 1 \\
\hline $\mathrm{HT}_{\operatorname{cost}(\mathrm{i})}$ & 4500 & 5000 & 550 & 560 & 900 & 170 & 260 & 30 & 30 & 30 \\
\hline $\mathrm{CD}_{\operatorname{cost}(\mathrm{i})}$ & 9000 & 10000 & 1100 & 1120 & 1800 & 340 & 520 & 60 & 60 & 60 \\
\hline $\mathrm{CD}_{\text {hour(i) }}$ & 5 & 5 & 4 & 4 & 4 & 2 & 2 & 0 & 0 & 0 \\
\hline I state & 8 & 8 & -5 & -5 & -6 & -3 & -3 & -1 & -1 & -1 \\
\hline
\end{tabular}

Table 2. Forecasted load pattern and spot prices

\begin{tabular}{cccccc}
\hline $\begin{array}{c}\text { Hours } \\
(\mathrm{h})\end{array}$ & $\begin{array}{c}\text { Load } \\
(\mathrm{MW})\end{array}$ & $\begin{array}{c}\text { Spot } \\
\text { price } \\
(\text { Rs/MWh })\end{array}$ & $\begin{array}{c}\text { Hours } \\
(\mathrm{h})\end{array}$ & $\begin{array}{c}\text { Load } \\
(\mathrm{MW})\end{array}$ & $\begin{array}{c}\text { Spot price } \\
(\mathrm{Rs} / \mathrm{MWh})\end{array}$ \\
\hline 1 & 700 & 996.75 & 13 & 1400 & 1107.00 \\
\hline 2 & 750 & 990 & 14 & 1300 & 1102.50 \\
\hline 3 & 850 & 1039.5 & 15 & 1200 & 1012.50 \\
\hline 4 & 950 & 1019.25 & 16 & 1050 & 1003.50 \\
\hline 5 & 1000 & 1046.25 & 17 & 1000 & 1001.25 \\
\hline 6 & 1100 & 1032.75 & 18 & 1100 & 992.25 \\
\hline 7 & 1150 & 1012.5 & 19 & 1200 & 999.00 \\
\hline 8 & 1200 & 996.75 & 20 & 1400 & 1019.25 \\
\hline 9 & 1300 & 1026 & 21 & 1300 & 1039.50 \\
\hline 10 & 1400 & 1320.75 & 22 & 1100 & 1032.75 \\
\hline 11 & 1450 & 1356.75 & 23 & 900 & 1023.75 \\
\hline 12 & 1500 & 1424.25 & 24 & 800 & 1014.75 \\
\hline
\end{tabular}

Table 3. Emission coefficients of 10 generating units

\begin{tabular}{cccc}
\hline Units & $\begin{array}{c}\alpha_{\mathrm{i}} \\
\text { (ton/MW' }\end{array}$ & $\beta_{\mathrm{i}}$ (ton/MWh) & $\begin{array}{c}\gamma_{\mathrm{i}} \\
\text { (ton/h) }\end{array}$ \\
\hline 1 & 0.00312 & -0.24444 & 10.33908 \\
\hline 2 & 0.00312 & -0.24444 & 10.33908 \\
\hline 3 & 0.00509 & -0.40695 & 30.0391 \\
\hline 4 & 0.00509 & -0.40695 & 30.0391 \\
\hline 5 & 0.00344 & -0.38132 & 32.00006 \\
\hline 6 & 0.00344 & -0.38132 & 32.00006 \\
\hline 7 & 0.00465 & -0.39023 & 33.00056 \\
\hline 8 & 0.00465 & -0.39023 & 33.00056 \\
\hline 9 & 0.00465 & -0.39524 & 35.00056 \\
\hline 10 & 0.0047 & -0.39864 & 36.00012 \\
\hline
\end{tabular}

Table 4. Parameter selection for proposed algorithm

\begin{tabular}{ll}
\hline Parameter & Chosen value \\
\hline Number of chromosomes & 20 \\
\hline Chromosome size & 24 (hours) X 10(generators) \\
\hline Max number of generations & 100 \\
\hline Mutation probability & 0.05 \\
\hline Number of particles & 20 \\
\hline Inertia weight factors & Wmax $=0.9$ and Wmin $=0.4$ \\
\hline Velocity limits & $\mathrm{Vmax}=25$ and Vmin $=-25$ \\
\hline Acceleration coefficients & $\mathrm{C} 1=2$ and $\mathrm{C} 2=2$ \\
\hline Tabu list Size & 10 \\
\hline Mutation probability & 0.05 \\
\hline Number of particles & 20 \\
\hline Inertia weight factors & $\mathrm{Wmax}=0.9$ and Wmin $=0.4$ \\
\hline Velocity limits & $\mathrm{Vmax}=25$ and Vmin $=-25$ \\
\hline Acceleration coefficients & $\mathrm{C} 1=2$ and $\mathrm{C} 2=2$ \\
\hline Tabu list Size & 10 \\
\hline
\end{tabular}

The traditional unit commitment which exactly satisfies the equality constraint is solved by the proposed algorithm and the results are shown in Table 5. The profit based unit commitment problem without emission limitation has been solved by the proposed hybrid PSO algorithm and provided in Table 6. The proposed hybrid PSO algorithm has been applied for the solution of PBUC with emission limitations and solution is given in Table 7. The optimal PBUC solution obtained for the example problem has been compared with the solution of SFLA algorithm [16]. Fig 3 shows the revenue, fuel cost and profit during each hour of the optimal solution obtained for the PBUC by the proposed algorithm on the 10 unit system over 24 hour time horizon. Fig 4 and Fig 5 gives the comparison of hour by hour profit and emission obtained for the PBUC and traditional UC by proposed algorithm respectively. Fig 6 shows the comparison of forecasted power with generated power of PBUC solution on 10 unit system over 24 hours period. Fig 7 shows the convergence characteristics of the proposed algorithm for PBUC solution. From the convergence characteristics, it is observed that the optimal solution for PBUC at a daily profit of Rs.4787409 is reached within the maximum number of generations defined in the parameter selection. 
Table 5. Traditional UC by proposed algorithm

\begin{tabular}{|c|c|c|c|c|c|c|c|c|c|c|c|c|c|c|c|}
\hline Hours & $\mathrm{U} 1$ & $\mathrm{U} 2$ & U3 & $\mathrm{U} 4$ & U5 & U6 & U7 & U8 & U9 & U10 & $\begin{array}{c}\text { Fuel } \\
\text { Cost (Rs) }\end{array}$ & $\begin{array}{c}\text { Startup } \\
\text { cost } \\
(\mathrm{Rs})\end{array}$ & $\begin{array}{l}\text { Revenue } \\
\text { (Rs) }\end{array}$ & Profit (Rs) & $\begin{array}{c}\text { Emission } \\
\text { (tons) }\end{array}$ \\
\hline 1 & 455 & 245 & 0 & 0 & 0 & 0 & 0 & 0 & 0 & 0 & 614968.2 & 0 & 697725 & 82756.8 & 682.766 \\
\hline 2 & 455 & 295 & 0 & 0 & 0 & 0 & 0 & 0 & 0 & 0 & 654167.7 & 0 & 742500 & 38332.3 & 754.784 \\
\hline 3 & 455 & 395 & 0 & 0 & 0 & 0 & 0 & 0 & 0 & 0 & 732769.2 & 0 & 883575 & 150805.8 & 945.620 \\
\hline 4 & 455 & 455 & 0 & 40 & 0 & 0 & 0 & 0 & 0 & 0 & 840510.9 & 25200 & 968287.5 & 102576.6 & 1111.978 \\
\hline 5 & 455 & 455 & 0 & 90 & 0 & 0 & 0 & 0 & 0 & 0 & 878250.15 & 0 & 104 & 167999.85 & 1124.716 \\
\hline 6 & 455 & 455 & 0 & 130 & 60 & 0 & 0 & 0 & 0 & 0 & 982853.55 & 40500 & 11 & 1.45 & 1174.735 \\
\hline 7 & 455 & 455 & 0 & 130 & 110 & 0 & 0 & 0 & 0 & 0 & 1028670.3 & 0 & 116 & 4.7 & 1184.909 \\
\hline 8 & 455 & 455 & 0 & 130 & 160 & 0 & 0 & 0 & 0 & 0 & 1077250.5 & 0 & $11 \mathrm{C}$ & 118 & 1212.283 \\
\hline 9 & 455 & 455 & 0 & 130 & 162 & 73 & 25 & 0 & 0 & 0 & 1221757.2 & 19350 & 133 & 2.8 & 1262.382 \\
\hline 10 & 455 & 455 & 130 & 130 & 162 & 40 & 28 & 0 & 0 & 0 & 1351888.2 & 24750 & 184 & 472411.8 & 1324.863 \\
\hline 11 & 455 & 455 & 130 & 130 & 162 & 80 & 38 & 0 & 0 & 0 & 1375761.15 & 0 & 196 & 591526.35 & 1325.289 \\
\hline 12 & 455 & 455 & 130 & 130 & 162 & 80 & 78 & 0 & 10 & 0 & 14700 & 1350 & 2136375.01 & 665019.01 & 13 \\
\hline 13 & 455 & 455 & 130 & 130 & 162 & 68 & 0 & 0 & 0 & 0 & 1293 & 0 & 1 & 256175.55 & 1298.869 \\
\hline 14 & 455 & 455 & 130 & 130 & 130 & 0 & 0 & 0 & 0 & 0 & 1177373.7 & 0 & 1433250 & 255876.3 & 1256.951 \\
\hline 15 & 455 & 455 & 0 & 130 & 160 & 0 & 0 & 0 & 0 & 0 & 1075 & 0 & 1215000 & 139635.45 & 1212.283 \\
\hline 16 & 455 & 455 & 0 & 130 & 0 & 0 & 0 & 0 & 0 & 10 & 878250.15 & 1350 & 1053675 & 174074.85 & 1182.793 \\
\hline 17 & 455 & 455 & 0 & 90 & 0 & 0 & 0 & 0 & 0 & 0 & 878250.15 & 0 & 1001250 & 122999.85 & 1124.716 \\
\hline 18 & 455 & 455 & 0 & 130 & 0 & 60 & 0 & 0 & 0 & 0 & 986683.95 & 7650 & 1091475 & 97141.04 & 1174.735 \\
\hline 19 & 455 & 455 & 0 & 130 & 0 & 80 & 80 & 0 & 0 & 0 & 1131351.75 & 19350 & 1198800 & 48098.25 & 1208.282 \\
\hline 20 & 455 & 455 & 130 & 130 & 0 & 80 & 85 & 10 & 0 & 55 & 1404634.05 & 22050 & 1426950 & 265.94 & 1330.442 \\
\hline 21 & 455 & 455 & 130 & 130 & 0 & 80 & 50 & 0 & 0 & 0 & 1222647.3 & 0 & 1351350 & 128702.7 & 1265.011 \\
\hline 22 & 455 & 455 & 130 & 0 & 0 & 60 & 0 & 0 & 0 & 0 & 988092.9 & 0 & 1136025.01 & 147932.11 & 1174.735 \\
\hline 23 & 455 & 400 & 45 & 0 & 0 & 0 & 0 & 0 & 0 & 0 & 802003.95 & 0 & 921375 & 119371.05 & 978.833 \\
\hline 24 & 455 & 300 & 45 & 0 & 0 & 0 & 0 & 0 & 0 & 0 & 723388.95 & 0 & 811800 & 88411.05 & 784.877 \\
\hline Total & & & & & & & & & & & 24790519 & 161550 & 29312100 & 4360031 & 27460.6 \\
\hline
\end{tabular}

Table 6. Profit based UC without emission limitations by proposed algorithm

\begin{tabular}{cccccccccccccccc}
\hline Hours & U1 & U2 & U3 & U4 & U5 & U6 & U7 & U8 & U9 & U10 & $\begin{array}{c}\text { Fuel } \\
\text { Cost (Rs) }\end{array}$ & $\begin{array}{c}\text { Startup } \\
\text { cost } \\
\text { (Rs) }\end{array}$ & $\begin{array}{c}\text { Revenue } \\
\text { (Rs) }\end{array}$ & $\begin{array}{c}\text { Profit } \\
\text { (Rs) }\end{array}$ & $\begin{array}{c}\text { Emission } \\
\text { (tons) }\end{array}$ \\
\hline $\mathbf{1}$ & 455 & 245 & 0 & 0 & 0 & 0 & 0 & 0 & 0 & 0 & 614968.515 & 0 & 697725 & 82756.49 & 682.7661 \\
\hline $\mathbf{2}$ & 455 & 295 & 0 & 0 & 0 & 0 & 0 & 0 & 0 & 0 & 654168.015 & 0 & 742500 & 88331.99 & 754.7841 \\
\hline $\mathbf{3}$ & 455 & 395 & 0 & 0 & 0 & 0 & 0 & 0 & 0 & 0 & 732769.515 & 0 & 883575 & 150805.5 & 945.6201 \\
\hline $\mathbf{4}$ & 455 & 455 & 0 & 0 & 0 & 0 & 0 & 0 & 0 & 0 & 780060.015 & 0 & 927517.5 & 147457.5 & 1090.073 \\
\hline $\mathbf{5}$ & 455 & 455 & 0 & 0 & 0 & 0 & 0 & 0 & 0 & 0 & 780060.015 & 0 & 952087.5 & 172027.5 & 1090.073 \\
\hline $\mathbf{6}$ & 455 & 455 & 0 & 130 & 0 & 0 & 0 & 0 & 0 & 0 & 908781.75 & 25200 & 1074060 & 140078.3 & 1153.230 \\
\hline $\mathbf{7}$ & 455 & 455 & 0 & 130 & 0 & 0 & 0 & 0 & 0 & 0 & 908781.75 & 0 & 1053000 & 144218.3 & 1153.230 \\
\hline
\end{tabular}




\begin{tabular}{|c|c|c|c|c|c|c|c|c|c|c|c|c|c|c|c|}
\hline 8 & 455 & 455 & 130 & 130 & 0 & 0 & 0 & 0 & 0 & 0 & 1038912.75 & 24750 & 1166198 & 102535.3 & 1216.386 \\
\hline 9 & 455 & 455 & 130 & 130 & 0 & 0 & 0 & 0 & 0 & 0 & 1038912.75 & 0 & 1200420 & 161507.3 & 1216.386 \\
\hline 10 & 455 & 455 & 130 & 130 & 162 & 0 & 0 & 0 & 0 & 0 & 1207381.5 & 40500 & 1759239 & 511357.5 & 1276.892 \\
\hline 11 & 455 & 455 & 130 & 130 & 162 & 80 & 0 & 0 & 0 & 0 & 1306212.3 & 7650 & 1915731 & 601868.7 & 1300.403 \\
\hline 12 & 455 & 455 & 130 & 130 & 162 & 80 & 0 & 0 & 0 & 0 & 1306212.3 & 0 & 2011041 & 704828.7 & 1300.403 \\
\hline 13 & 455 & 455 & 130 & 130 & 162 & 68 & 0 & 0 & 0 & 0 & 1293624.45 & 0 & 1549800 & 256175.6 & 1300.403 \\
\hline 14 & 455 & 455 & 0 & 130 & 162 & 0 & 0 & 0 & 0 & 0 & 1077250.5 & 0 & 1325205 & 247954.5 & 1213.735 \\
\hline 15 & 455 & 455 & 0 & 130 & 100 & 0 & 0 & 0 & 0 & 0 & 1019436.75 & 0 & 1154250 & 134813.3 & 1213.735 \\
\hline 16 & 455 & 455 & 0 & 100 & 25 & 0 & 0 & 0 & 0 & 0 & 928377 & 0 & 1038623 & 110246.0 & 1213.735 \\
\hline 17 & 455 & 455 & 0 & 30 & 35 & 0 & 0 & 0 & 0 & 0 & 884511.9 & 0 & 976218.75 & 91706.85 & 1135.34 \\
\hline 18 & 455 & 455 & 0 & 130 & 60 & 0 & 0 & 0 & 0 & 0 & 982853.55 & 0 & 1081553 & 98699.45 & 1174.735 \\
\hline 19 & 455 & 455 & 0 & 130 & 160 & 0 & 0 & 0 & 0 & 0 & 1075364.865 & 0 & 1188810 & 113445.1 & 1213.735 \\
\hline 20 & 455 & 455 & 0 & 130 & 162 & 0 & 0 & 0 & 0 & 0 & 1077250.5 & 0 & 1225139 & 147888.5 & 1213.735 \\
\hline 21 & 455 & 455 & 0 & 130 & 162 & 0 & 0 & 0 & 0 & 0 & 1077250.5 & 0 & 1249479 & 172228.5 & 1213.735 \\
\hline 22 & 455 & 455 & 0 & 130 & 0 & 0 & 0 & 0 & 0 & 0 & 908781.75 & 0 & 1074060 & 165278.3 & 1154.934 \\
\hline 23 & 455 & 445 & 0 & 0 & 0 & 0 & 0 & 0 & 0 & 0 & 772168.5 & 0 & 921375 & 149206.5 & 1064.438 \\
\hline 24 & 455 & 345 & 0 & 0 & 0 & 0 & 0 & 0 & 0 & 0 & 658091.7 & 0 & 811800 & 153708.3 & 842.4021 \\
\hline \multicolumn{11}{|c|}{ Total } & 23032183.14 & 98100 & 27979406.9 & 4849125 & 27135 \\
\hline
\end{tabular}

Table 7. PBUC with emission limitation by proposed algorithm

\begin{tabular}{|c|c|c|c|c|c|c|c|c|c|c|c|c|c|c|c|}
\hline Hours & U1 & U2 & U3 & $\mathrm{U} 4$ & U5 & U6 & U7 & U8 & U9 & U10 & $\begin{array}{c}\text { Fuel } \\
\text { Cost (Rs) }\end{array}$ & $\begin{array}{c}\text { Startup } \\
\text { cost } \\
\text { (Rs) }\end{array}$ & $\begin{array}{l}\text { Revenue } \\
\text { (Rs) }\end{array}$ & $\begin{array}{l}\text { Profit } \\
\text { (Rs) }\end{array}$ & $\begin{array}{l}\text { Emission } \\
\text { (ton) }\end{array}$ \\
\hline 1 & 455 & 245 & 0 & 0 & 0 & 0 & 0 & 0 & 0 & 0 & 615741 & 0 & 697725 & 81984 & 682.8 \\
\hline 2 & 455 & 295 & 0 & 0 & 0 & 0 & 0 & 0 & 0 & 0 & 654953 & 0 & 742500 & 87547 & 754.8 \\
\hline 3 & 455 & 395 & 0 & 0 & 0 & 0 & 0 & 0 & 0 & 0 & 733585 & 0 & 883575 & 149990 & 945.6 \\
\hline 4 & 455 & 455 & 0 & 0 & 0 & 0 & 0 & 0 & 0 & 0 & 780899 & 0 & 927518 & 146619 & 1090.1 \\
\hline 5 & 455 & 455 & 0 & 0 & 0 & 0 & 0 & 0 & 0 & 0 & 780898.5 & 0 & 952087.5 & 171189 & 1090.1 \\
\hline 6 & 455 & 455 & 0 & 130 & 0 & 0 & 0 & 0 & 0 & 0 & 909628 & 25200 & 1074060 & 139232 & 1153.2 \\
\hline 7 & 455 & 455 & 0 & 130 & 0 & 0 & 0 & 0 & 0 & 0 & 909628 & 0 & 1053000 & 143372 & 1153.2 \\
\hline 8 & 455 & 455 & 130 & 130 & 0 & 0 & 0 & 0 & 0 & 0 & 1039759 & 24750 & 1166198 & 101689 & 1216.4 \\
\hline 9 & 455 & 455 & 130 & 130 & 0 & 0 & 0 & 0 & 0 & 0 & 1039759 & 0 & 1200420 & 160661 & 1216.4 \\
\hline 10 & 455 & 455 & 130 & 130 & 162 & 0 & 0 & 0 & 0 & 0 & 1208322 & 40500 & 1759239 & 510417 & 1276.9 \\
\hline 11 & 455 & 455 & 130 & 130 & 162 & 80 & 0 & 0 & 0 & 0 & 1307159 & 7650 & 1915731 & 600922 & 1300.4 \\
\hline 12 & 455 & 455 & 130 & 130 & 162 & 80 & 0 & 0 & 0 & 0 & 1307159 & 0 & 2011041 & 703882 & 1300.4 \\
\hline 13 & 455 & 455 & 130 & 130 & 162 & 68 & 0 & 0 & 0 & 0 & 1294570 & 0 & 1549800 & 255230 & 1298.9 \\
\hline 14 & 455 & 455 & 130 & 130 & 130 & 0 & 0 & 0 & 0 & 0 & 1178281 & 0 & 1433250 & 254969 & 1257 \\
\hline 15 & 455 & 455 & 0 & 130 & 160 & 0 & 0 & 0 & 0 & 0 & 1076303 & 0 & 1215000 & 138697 & 1242.3 \\
\hline 16 & 455 & 305 & 0 & 130 & 160 & 0 & 0 & 0 & 0 & 0 & 958208 & 0 & 1053675 & 95467 & 893.3 \\
\hline 17 & 415 & 295 & 0 & 130 & 160 & 0 & 0 & 0 & 0 & 0 & 920463 & 0 & 1001250 & 80787 & 808.2 \\
\hline
\end{tabular}




\begin{tabular}{|c|c|c|c|c|c|c|c|c|c|c|c|c|c|c|c|}
\hline 18 & 455 & 353 & 0 & 130 & 162 & 0 & 0 & 0 & 0 & 0 & 997818 & 0 & 1091475 & 93657 & 981.5 \\
\hline 19 & 455 & 455 & 0 & 130 & 160 & 0 & 0 & 0 & 0 & 0 & 1076303 & 0 & 1198800 & 122497 & 1242.3 \\
\hline 20 & 455 & 455 & 0 & 130 & 162 & 0 & 0 & 0 & 0 & 0 & 1078192 & 0 & 1225139 & 146947 & 1243.8 \\
\hline 21 & 455 & 455 & 0 & 130 & 162 & 0 & 0 & 0 & 0 & 0 & 1078192 & 0 & 1249479 & 171287 & 1243.8 \\
\hline 22 & 455 & 455 & 0 & 130 & 0 & 0 & 0 & 0 & 0 & 0 & 909628 & 0 & 1074060 & 164432 & 1153.2 \\
\hline 23 & 455 & 445 & 0 & 0 & 0 & 0 & 0 & 0 & 0 & 0 & 773006 & 0 & 921375 & 148369 & 1060.4 \\
\hline 24 & 455 & 345 & 0 & 0 & 0 & 0 & 0 & 0 & 0 & 0 & 694234 & 0 & 811800 & 117566 & 842.4 \\
\hline \multicolumn{11}{|c|}{ Total } & 23322689 & 98100 & 28208198 & 4787409 & 26447.4 \\
\hline
\end{tabular}

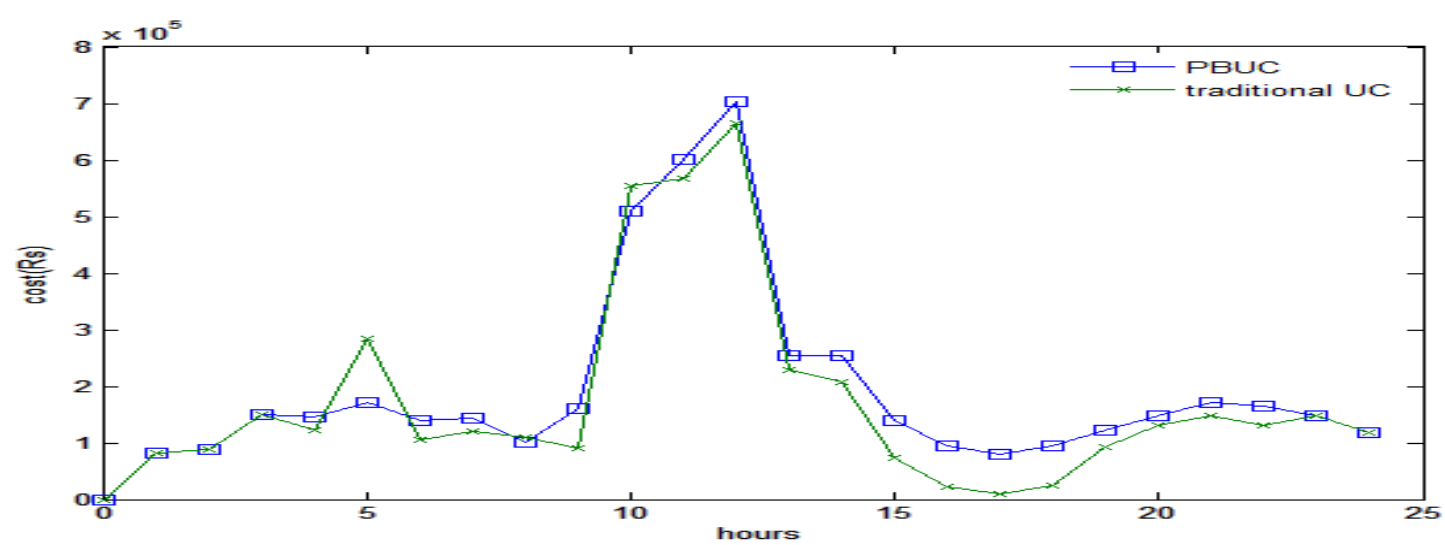

Fig 3. Revenue, fuel cost and profit for PBUC by proposed algorithm

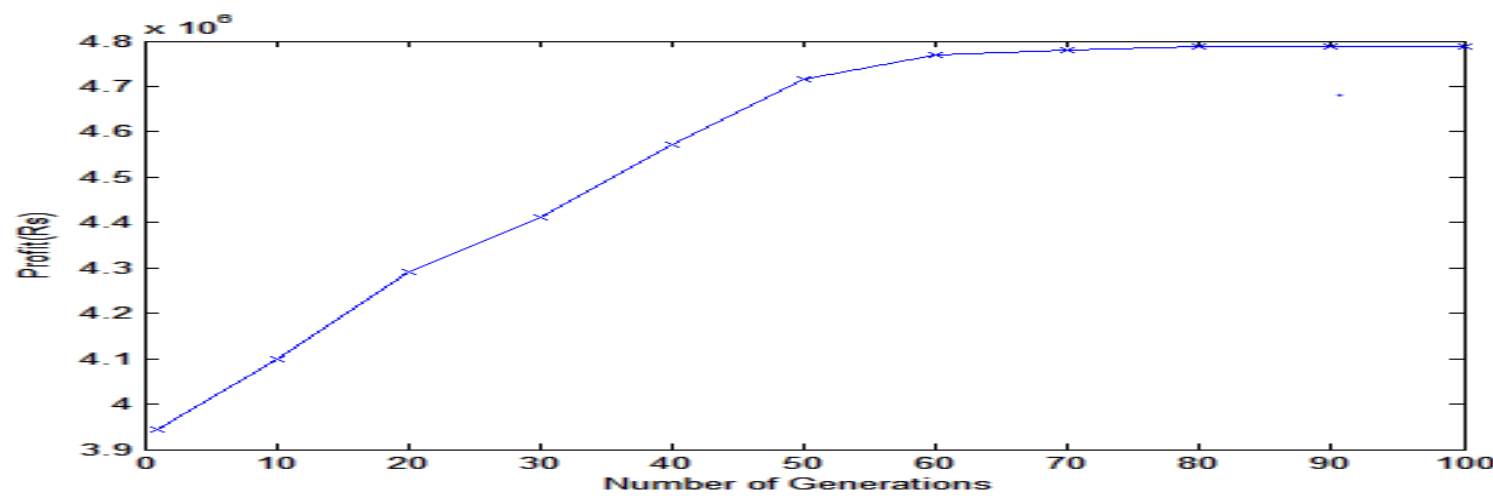

Fig. 4. Comparison of profits in PBUC and traditional UC by proposed algorithm

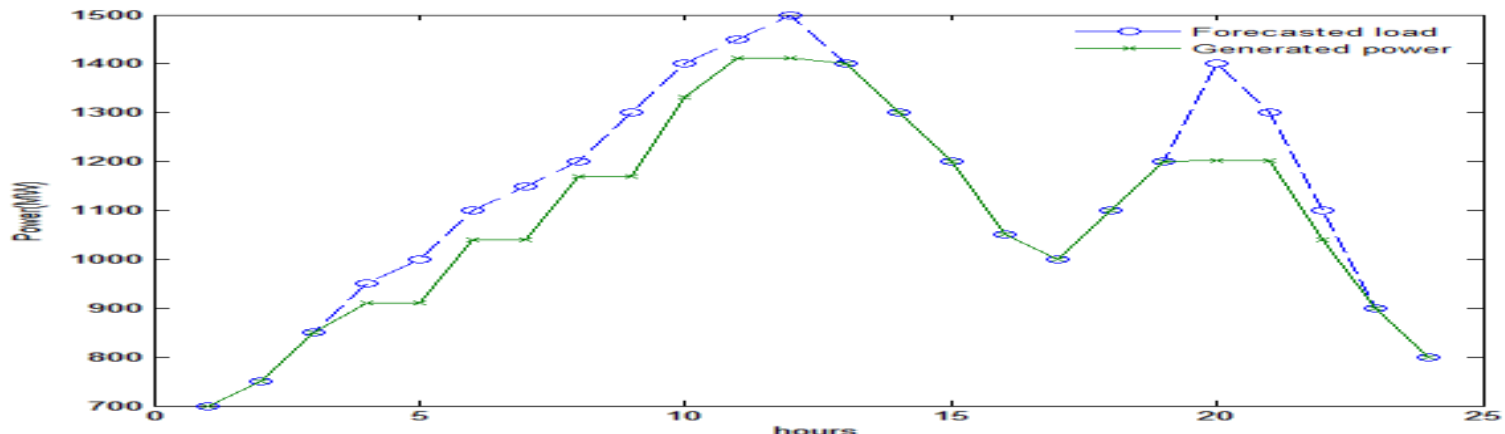

Fig. 5. Comparison between forecasted load and generated power for PBUC. 


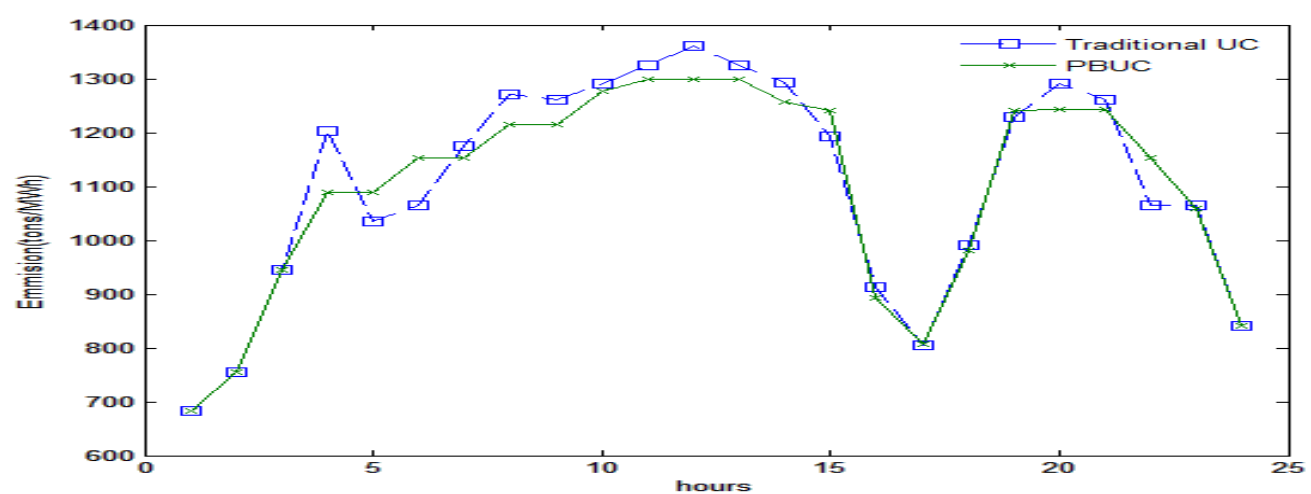

Fig. 6. Comparison of emissions in PBUC and traditional UC

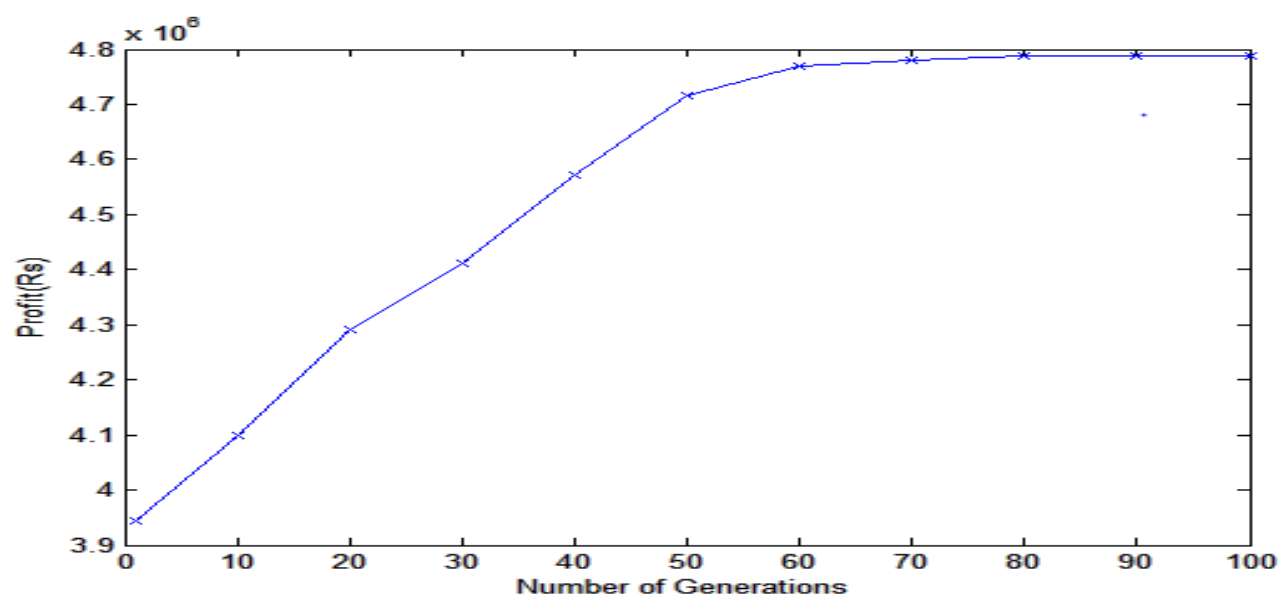

Fig. 7. Convergence characteristics of proposed algorithm for PBUC

Table 8 gives the solution obtained by the proposed algorithm for traditional unit commitment and PBUC with and without emission limitations. The traditional unit commitment is the one in which the objective function is minimization of the total production cost provided all the system constraints are satisfied. The solution obtained by the proposed algorithm for the traditional UC has been compared with SFLA method and IABC algorithm as shown in table 9 and is found that the proposed HPSO algorithm has given a highest daily profit of Rs.4360031. From the table 9, it is observed that a daily profit of Rs. 4849125 for profit based unit commitment without emission limitations has been obtained by proposed algorithm which is better than other methods such as IABC algorithm, Muller's method and ACO method. The solution of PBUC with emission limitations obtained by proposed method has been compared with the SFLA based PBUC solution and has been proved that the proposed method has given a solution with profit and emission of Rs.4787409 and 26447.4 tons respectively which are better than the SFLA based solution. From the results obtained, it is proved that the proposed hybrid algorithm along with the tabu concepts has given solution with maximum profit and minimum emission than the other methods addressed in the literature.

\section{CONCLUSION}

In this paper, the profit based unit commitment problem with emission limitations in a restructured power market has been solved by a hybrid algorithm which is formulated by integrating the concepts of Evolutionary Programming and
Particle Swarm Optimization with tabu search. In the nonlinear solution space of PBUC problem, the EP and PSO are enabling the proposed algorithm to identify the high performance region of the solution space. The more promising region of the solution space is then completely explored for the global optimal solution by maintaining Tabu list and Aspiration criterion. An IEEE 39 bus test system with 10 generating units has been taken from the literature and the proposed algorithm is applied for traditional UC and PBUC solution with and without emission limitations. The result obtained by the proposed algorithm for traditional UC has been compared with SFLA method and IABC algorithm. It is found that the profit obtained by proposed algorithm is greater than other methods. The solution obtained for the PBUC problem without emission limitations by proposed algorithm has been compared with IABC algorithm, Muller's method and ACO method. The proposed method has given a daily profit of Rs. 4849125 which is better than other methods. A daily profit of Rs.4787409 with a daily emission of 26447.4 tons has been obtained for the solution of PBUC with emission limitations and has been compared with SFLA method. From the comparison of results and convergence characteristics of the proposed algorithm, the capability of the proposed algorithm for handling equality and inequality constraints and hence the ability of the proposed algorithm for solving nonlinear optimization problems have been established. It is demonstrated that the proposed hybrid algorithm can be applied for solving large scale unit commitment problems in deregulated power market. 
Table 8. Traditional UC and PBUC Solutions obtained by the proposed hybrid PSO algorithm

\begin{tabular}{|c|c|c|c|c|c|}
\hline Sl.No & Solution & Daily Profit (Rs) & Annual Profit (Rs) & $\begin{array}{l}\text { Daily Emission } \\
\text { (tons) }\end{array}$ & $\begin{array}{l}\text { Annual Emission } \\
\text { (tons) }\end{array}$ \\
\hline 1 & Traditional UC & 4360031 & 1591411315 & 27460.6 & 10023119 \\
\hline 2 & $\begin{array}{c}\text { PBUC without } \\
\text { emission } \\
\text { limitations }\end{array}$ & 4849125 & 1769930625 & 27135 & 9904275 \\
\hline 3 & $\begin{array}{l}\text { PBUC with } \\
\text { emission } \\
\text { limitations }\end{array}$ & 4787409 & 1747404285 & 26447.4 & 9653301 \\
\hline
\end{tabular}

Table 9. Comparison of solution obtained by the proposed algorithm with SFLA method

\begin{tabular}{|c|c|c|c|c|c|c|}
\hline Sl.No & Solution & Method & Daily Profit (Rs) & Annual Profit (Rs) & $\begin{array}{l}\text { Daily Emission } \\
\text { (tons) }\end{array}$ & $\begin{array}{l}\text { Annual Emission } \\
\text { (tons) }\end{array}$ \\
\hline \multirow{3}{*}{1} & \multirow{3}{*}{$\begin{array}{c}\text { Traditional } \\
\text { UC }\end{array}$} & $\begin{array}{c}\text { SFLA } \\
\text { Method[16] }\end{array}$ & 3661454 & 1336430827 & 28244.15 & 10309114.75 \\
\hline & & $\begin{array}{c}\text { IABC } \\
\text { algorithm[26] }\end{array}$ & 4321574 & 1577374510 & 27609 & 10077285 \\
\hline & & $\begin{array}{l}\text { Proposed hybrid } \\
\text { PSO algorithm }\end{array}$ & 4360031 & 1591411315 & 27460.6 & 10023119 \\
\hline \multirow{4}{*}{2} & \multirow{4}{*}{$\begin{array}{c}\text { PBUC } \\
\text { without } \\
\text { emission } \\
\text { limitations }\end{array}$} & $\begin{array}{c}\text { IABC algorithm } \\
{[26]}\end{array}$ & 4834334 & 1764531910 & 26551 & 9691115 \\
\hline & & $\begin{array}{c}\text { Muller method } \\
{[29]}\end{array}$ & 4648320 & 1696636800 & - & - \\
\hline & & $\begin{array}{c}\text { ACO method } \\
\text { [11] }\end{array}$ & 4675050 & 1706393250 & - & - \\
\hline & & $\begin{array}{l}\text { Proposed hybrid } \\
\text { PSO algorithm }\end{array}$ & 4849125 & 1769930625 & 27135 & 9904275 \\
\hline \multirow{2}{*}{3} & \multirow{2}{*}{$\begin{array}{l}\text { PBUC with } \\
\text { emission } \\
\text { limitations }\end{array}$} & $\begin{array}{c}\text { SFLA Method } \\
{[16]}\end{array}$ & 4744910.1 & 1731892187 & 26617.6 & 9715412 \\
\hline & & $\begin{array}{l}\text { Proposed hybrid } \\
\text { PSO algorithm }\end{array}$ & 4787409 & 1747404285 & 26447.4 & 9653301 \\
\hline
\end{tabular}

\section{REFERENCES}

[1] Wood, AJ., Wollenberg, BF., 1984, Power generation, operation and control, New York, John Willey \& Sons.

[2] Narayana Prasad Padhy., Unit commitment - A bibliographical Survey, IEEE Transactions on Power Systems. 19(2), (2004), 1196-1205.

[3] Vossoghi Mahdi., Vossoghi Ali., Vossoghi Mohammed and Bavaza, MS., A new hybrid method to profit-based unit commitment for minimum performance of ISO. International conference on systems, science and engineering(ICSSE), (2012), 147-151.

[4] Jacob Raglend., Raghuveer., Rakesh Avinash., Padhy and Kathari. Solution to profit based unit commitment problem using Particle swarm optimization. Journal of Applied soft computing, 10(4), 2010, 1247-1256.

[5] Mantawy. AH., Abdel-Magid YL., Selim SZ, Integrating genetic algorithms, tabu search and simulated annealing for the unit commitment problem. IEEE Transactions on Power Systems. 14(3), 1999, 829-836.

[6] Bo Lu., Shahidehpour, SM. Unit Commitment with Flexible Generating Units. IEEE Transactions on Power Systems. 20(2). 2005. 1022-1034.

[7] Yamin, HY., El-Dwairi, Q., Shahidehpour, SM. A new approach for Gencos profit based unit commitment in day-ahead competitive electricity markets considering reserve uncertainty. International Journal of Electrical power and energy systems. 29(8), 2007, 609-616.

[8] Richter, CW., Sheble, G. A profit-based unit commitment GA for the competitive environment. IEEE transaction on power systems. 15(2), 2000, 715 721.

[9] Attaviriyanupap, P., Kita, H., Tanaka Eiichi.,Hasegawa,J ., A Hybrid LR-EP for solving new profit-based UC problem under competitive environment. IEEE transactio ns on power systems. 18(1), 2003, 229-237.

[10] Yuan Xiaohui., Yuan Yanbin., Wang Cheng., Zhang Xiaopan. An Improved PSO approach for profit-based unit commitment in Electricity market. IEEE PES conference on Transmission and distribution and exhibition.2005, pp. 1-4.

[11] Columbus Christopher, C,. Chandrasekaran, K., Sishaj, P., Simon. Nodal ant colony optimization for solving PBUC problem for GENCOs. Journal of applied soft computing, 12(1), 2012, 145-160.

[12] Catalao, JPS., Mariano, SJPS., V M F Mendes and L A FM Ferreira. A practical approach for profit based unit c ommitment with emission limitations. International Joura 1 of Electrical power and energy systems. 32(3), 2010 218-224, 
[13] Gent, MR., Lamont, J W., Minimum-emission dispatch, IEEE transactions on Power apparatus and systems. 90(6), 1971, 2650-2660.

[14] Nanda, J., Kothari, DP., Srivastava, SC., New optimal power-dispatch algorithm using Fletcher's quadratic programming method. IEE proceedings on generation, transmission and distribution. Part C. 136(3), 1989, 153161.

[15] Hota, PK., Chakrabarti. R., Chattopadhyay, K., Economi c emission load dispatch with flow constraints using sequential quadratic programming technique. Journal of Institution of Engineers (India)-Electrical Part. 81(2), $2000,21-25$

[16] Venkatesan., T, Sanavullah., SFLA approach to solve PBUC problem with emission limitation. International Journal of Electrical power and energy systems. 46, 2013 $1-9$.

[17] Kit Po Wang., Yuryevich, J., Evolutionary-programming based algorithm for environmentally-constrained economic dispatch. IEEE Transactions on Power Systems. 13(2), 1998, 301-306.

[18] Wu, QH., Ma, JT., Power system optimal reactive power dispatch using evolutionary programming. IEEE transactions on Power systems. 10(3), 1995, 1243-1249.

[19] Govardhan, M., Roy, R., Evolutionary computation based unit commitment using Hybrid priority list approach. IEEE International conference on Power and Energy (PECon). 2012, 245-250.

[20] Zwe-Lee Gaing., Particle Swarm Optimization to solving the economic dispatch considering the generator constraints. IEEE transactions on Power systems, 18 (3), 2003, 1187-1195.

[21] Sadati, N., Hajian M., Zamani, M., Unit commitment using particle swarm based simulated annealing optimization approach. IEEE Swarm intelligence symposium (SIS), 2007, 297-302.

[22] Tsung-Ying Lee, Optimal spinning reserve for a windthermal power system using EIPSO. IEEE transactions on Power systems. 22(4), 2007, 1612-1621.

[23] Chao-Ming Huang., Chi-Jen Huang., Ming-Li Wang., A particle swarm optimization to identifying the ARMAX model for short-term load forecasting. IEEE transactions on Power systems. 20(2), 2005, 1126-1133.

[24] Fred Glover and Manuel Laguna, Tabu search, Kluwer Academic publishers, Massachusetts, 1997, USA.

[25] Lakshmi, K., Vasantharathna, V., Hybrid artificial immune system approach for profit based unit commitme ntproblem. Journal of Electrical Engineering andTechnol ogy, 8(5), 2013, 959-968.

[26] Shanmuga sundaram, C., Sudhakaran,M., Selvakumar, R., Natarajan RG. Solution to profit based unit commitment using swarm intelligence technique. IEEE sponsored International conference on computation of power, energy, information and communication (ICCPEIC-2014). 2014, 258-263.

[27] Victoire, TAA., JeyakumarAE., Unit commitment by a tabu search based hybrid optimization technique. IEE proceedings on generation, transmission and distribution, 152(4), 2005, 563-574.

[28] Venkatesan, K., Selvakumar, C., Christopher Asir Rajan., EP based PSO algorithm for solving multi-area unit commitment problem with import and export constraints. Journal of Electrical Engineering and Technology. 9(2), 2014, 415-422.

[29] Chandran, K., Subrahmanyam, N., Sydulu, M., New approach with Muller method for Profit Based Unit Commitment. Proceedings of IEE Power and Energy Society General Meeting. 2008, 1-8. 